\title{
Grounded Disease: Constructing the Social from the Biological in Medicine
}

\author{
Shane N. Glackin
}

\begin{abstract}
Social Constructivism about the disease concept has generally been taken to ignore the fundamental biological reality underlying diseases, as well as to fall foul of several apparently compelling objections. In this paper I explain how the metaphysical relation of grounding can be used to tie a socially-constructed account of diseases and their classification to their underlying biological and behavioural states. I then generalise the position by disambiguating several varieties of normativism, including a particularly strong version of social constructivism, and showing that the grounding approach is available to each. I go on to provide what I believe to be the first attempt at a full semantics for diseasetalk and disagreement, before showing on that basis that the most troublesome objections to these positions can be avoided.
\end{abstract}

Keywords: Biology; Disease; Grounding; Medicine; Normativism; Social Constructivism.

\section{Introduction}

The effort to define the concept 'disease' is of philosophical and clinical interest in its own right; but insofar as it affects when and where people seek or are offered medical treatment, it is also of moral and social importance. ${ }^{1}$ Traditionally, the debate has split between normativists, who think the concept is inherently evaluative, and naturalists who think it is purely empirical. But normativism has for too long lacked a clearly-articulated

${ }^{1}$ See Reiss \& Ankeny (2016). 
theoretical footing, and the ongoing failure to provide one has exposed its adherents to various criticisms.

My aim in this paper is to provide that footing, thereby clarifying some aspects of normativism about disease, illness, and disability. ${ }^{2}$ I think the criticisms in question are misconceived, and rest on a misunderstanding; but normativists have in the past been remiss in explaining this convincingly. So in this paper I will spell out the metaphysical relation between social classification and biological classification which a normativist, and more specifically a social constructivist, account of the disease concept requires, before elaborating the way in which disagreements about disease-attributions can consequently be understood. I will then use this clarification as a basis to address the objections in question, as well as assessing to which of the positions which have been regarded as 'normativist' the defense is available.

My elaboration of normativism begins in section two, where I discuss the metaphysical relation of grounding, which I take to be the correct view of the relation between certain biological phenomena and the social practice of classifying them as diseases. This should not be regarded as a major innovation; I take it to be simply elaborating explicitly for the first time what has long been a tacit assumption of social constructivism, and I point out that a similar apparatus is available to rival theories. In section three I investigate the generality of this analysis more thoroughly by briefly summarising the various possible positions within the normativist-naturalist debate, before in that light sketching a particularly strong 'toy' version of social constructivism which can serve as a placeholder for the rest of the discussion. Since it can be seen that, with minor noted exceptions, neither the grounding

\footnotetext{
2 Though both good and bad reasons to regard these as conceptually separate have been adduced in the literature, I treat them as interchangeable for the purposes of the current analysis, and generally use 'disease' to refer to all three; nothing I say here should be taken to preclude the possibility of further distinguishing between them in the future. Following common usage in the literature, I've taken 'health' to denote the absence of disease, and vice versa.
} 
analysis nor the rejoinder to naturalist criticisms depends upon the particular features of the placeholder, both resources are generally available to normativists.

In sections four and five, I return to developing the analysis. Since my placeholder constructivism analyses the disease-concept as a specific kind of evaluative social judgement, the question of exactly who is to do the judging in which circumstances, and what is going on when they disagree, is dealt with in section four. In section five, finally, I address several variations on one of the most common objections to social constructivism in particular - and normativism in general - about the disease concept, which is that it leads to a pernicious (or alternatively, a fatuous) variety of relativism about sickness and health.

\section{Grounding the Social in the Biological}

According to social constructivists about the disease concept, whether or not someone has a disease, illness, or disability is more-or-less entirely - depending on the particular strain of social constructivism - a matter of some form of evaluative judgement. ${ }^{3}$ And this presents us with a rhetorical problem; diseases seem to be blithely, brutally indifferent to our opinions of them. As anyone who has advanced this view in public will have had pointed out to them; it doesn't matter how many happy thoughts we think about bowel cancer, it is still terminal. We can insist exasperatedly, until we are blue in the face, that of course this is not what we mean. But the incredulous stares remain; unfortunately, we have generally been rather too neglectful in saying precisely what it is that we do mean. In this section, I will try to rectify that oversight.

As a first step to the solution, we need to distinguish carefully between two sorts of philosophical question that can be asked about individual diseases. The first of these can be termed the status question; 'what must be true of an individual if she is to be reasonably attributed the status of having a particular illness?' The second will be the constitution

\footnotetext{
3 Social constructivism has generally been regarded as necessarily a normativist position. However, $c f$. Kingma (2013) for a dissenting view.
} 
question; 'what is the physical basis for a person's individual condition, if there is one?'4 Constitution questions look like the kind of thing that can be settled in objective, realist, stance-independent terms, if anything can; 5 one is either in the physical state of having bowel cancer, or one is not, regardless of what one thinks about the matter. But those terms won't settle the question social constructivists are interested in answering, which is related to the status question; what makes such conditions diseases?

This question, the one that social constructivists are concerned to answer, can in turn be called the general status question; 'what characterises the kind "disease"?' There must be some - possibly disjunctive - feature held in common by e.g. leukaemia, scaphoid fracture, and schizophrenia, but not by e.g. homosexuality, below-average height, or pierced ears. And social constructivists believe that what will count as plausible answers to the constitution question can't get us anywhere towards answering the general status question; lesions, or deviations from the statistical norm of functioning in a reference class, or harmful etiological dysfunctions (e.g. Szasz 1960; Boorse 1975; Boorse 1977; Wakefield 1992), are not even the right sort of thing to look to for an answer. The most plausible answer, we claim, is a particular sort of social attitude. And this means that disease status is not realist, or stanceindependent.

So social constructivists need now to say how these two contrasting sets of facts about categories based on stance-independent biological states and about those based on social attitudes - are related. And this is where, I think, we have been remiss in the past (e.g. Brown 1990; Cherry 1996; Engelhart 1976; Glackin 2010; Goosens 1980; Margolis 1976; Nordenfelt 2018; Reznek 1987).

\footnotetext{
4 I owe this distinction to my colleague Tom Roberts.

5 This is not an idle qualification; a substantial body of opinion in the philosophy of science regards all scientific judgement as being value-laden. For a particularly pertinent expression of this view, see Kincaid (2008). I don't think the version of normativism I espouse here is much affected by this; if the biological states grounding the social evaluative status of disease are themselves evaluative in character, then so be it. But it's a significant problem for rival naturalist theories, which hold that diseases can be identified on the basis of value-free empirical judgement alone.
} 
What should the relation look like? As normativists, and constructivists, we should not deny the obvious point that disease-states are objective natural phenomena. It is an objective, natural fact about a person - again, if anything is - that they have leukaemia, or a scaphoid fracture, or (assuming arguendo, but more controversially, the diagnostic validity of psychiatric disorders) schizophrenia. But normativists hold that it is a contingent fact about any such state that it is a disease, and does not reflect any intrinsic feature that it possesses; an individual in any of these objective natural states might or might not be properly regarded as diseased, depending upon other background factors. Naturalists may plausibly agree thus far; ${ }^{6}$ the defining feature of normativism is that it believes at least some of these additional factors to be evaluative.

A disease, then, will not be identical with the underlying biological or behavioural state, but it will be metaphysically dependent upon it. That is, the disease will necessarily exist whenever the underlying condition does, but only so long as some further background facts obtain. As long as those background facts obtain, however, the condition necessarily constitutes a disease. What sort of necessity is in operation here? For a normativist, it cannot be natural necessity, or the effect of laws of nature, since the class of biological and behavioural states concerned is heterogeneous, and does not constitute a natural kind on which such laws could (non-trivially) operate. The necessity is therefore a conceptual or semantic one; it concerns what is meant by classifying some such state or condition as a disease.

This might make the relation look like one of supervenience; ${ }^{7}$ although diseaseproperties are not simply reducible to the intrinsic properties of the underlying conditions, no change in disease-properties is possible without a change in the properties of the underlying condition. A patient cannot therefore cease to have bowel cancer just by fiat or

\footnotetext{
${ }^{6}$ According to Christopher Boorse's 'Biostatistical Theory' (BST), for instance, whether something counts as a disease depends centrally upon an extrinsic factor, namely its statistical prevalence in the reference population (Boorse 1975; Boorse 1977).

7 As I previously supposed; Glackin (2016: 312).
} 
volition; a change in this status requires a change in her underlying biological state. We would also, though, expect the supervenience to be global rather than local, since the relation between biological states and disease status is at least partly established by (widelydispersed) background evaluative facts rather than the intrinsic underlying properties alone. In that case, once we have specified the distribution of biological states and background facts across the whole world, we have fixed the distribution of disease-status. But for just this reason, supervenience cannot be the relation we are after. Remember, we want to be able to resist the idea that disease can be 'cured' just by changing our attitudes to it; we want to maintain a principled distinction between changing a patient's underlying clinical condition, and changing how we evaluate it. ${ }^{8}$ And that is just what we cannot do if our metaphysical setup leaves the biological facts and the background evaluative facts 'on all fours' together. 9

Fortunately, there is a more suitable metaphysical relation available, that of grounding. Grounding, unlike supervenience, is directional; rather than simple covariance ('no A-changes without B-changes'), it is concerned with the existence of objects, or properties, or facts, 'in virtue of' the existence of other, more fundamental ones (Cameron 2016: 383). In this instance, we shall say, the state of being ill or having a disease is grounded by the patient's underlying biological or behavioural state. And this grounding

\footnotetext{
8 Compare; we can reduce the level of child poverty either by taking steps to improve the financial situation of poor families, or by lowering the threshold level at which a family is defined as 'poor'. But only one of these actually alleviates any problem besides unflattering statistics.

9 I am immensely grateful to Adrian Currie for pointing out these problems to me, and for pointing me towards Epstein's model as a more satisfactory account. I don't here wish to rule out the possibility that a supervenience relation could be rigged to do the necessary job; some philosophers believe that anything grounding can be do can be done by supervenience too (see e.g. Wilson 2014). No such view has ever been elaborated in the literature, but if its details can be worked out satisfactorily then social constructivism could be rescued from the common objection by either route; I am not committed to a grounding account here except as one possible means to that rescue! Nevertheless, the directional aspect of grounding - discussed immediately below - makes it an intuitively more appealing approach; someone is ill, we typically want to say, because of or in virtue of their underlying state, and not just insofar as they are in it.
} 
relation, according to the social constructivist, in turn exists because the background evaluative facts are as they are.

The most richly detailed available model for the grounding of social facts is that recently developed by Brian Epstein $(2014 ; 2015) .{ }^{10}$ Grounding, in Epstein's model, is the standard grounding relation between (fundamental) grounding facts and the social facts which are metaphysically dependent upon them. Grounding takes place in a Frame, or 'a structure containing ... a set of possible worlds in which the grounding conditions for social facts are fixed in a particular way. Each of these possible worlds may have different grounding facts from one another' (Epstein 2015: 78). The frame is defined by a Frame Principle, which 'gives the grounding conditions not just for the actual world, but for all possibilities' (ibid.). The Frame Principle is in turn related to a further set of facts by the separate relation of Anchoring, whereby '(f)or a set of facts to anchor a frame principle is for those facts to be the metaphysical reason that the frame principle is the case' (op. cit.: 82).

As applied to the disease concept, the picture looks like this. To state that Malcolm has Mumps is to abbreviate a series of further statements about his underlying biological condition: that he is infected with rubulavirus; that his parotid and other salivary glands are inflamed; that he can infect other people by various forms of contact, etc. (WHO 2016: B26). These (or their abbreviation) are the grounding facts; they ground the judgement that Malcolm has a disease, that he is ill. And they do so just because in our actual world, as well as in the other possible worlds where grounding conditions are fixed in the same way - in our frame - those clinical facts are in fact what grounds the judgement that someone has a disease. Suppose that the grounding facts are different; Damo is in the biological state we term Mumps, but Malcolm is not. If the grounding conditions are the same in this other possible world - if it is in the same frame as ours - then Damo has the disease but Malcolm does not.

10Though see also Schaffer (2017); Schaffer (forthcoming). This summary draws on Schliesser (2015). 
What then is the frame principle, the thing which defines the frame, or the structure containing the possible worlds where the grounding conditions are fixed in exactly this particular way? Just the rule that the underlying conditions of (the set of clinical conditions abbreviated as) Mumps are in fact to ground the status of disease. That rule picks out all and only the possible worlds where those same conditions are thereby counted as diseases. And what establishes the frame principle? This is the distinctive feature of Epstein's model; the frame principle is anchored by some further set of facts. For a social constructivist, these anchoring facts concern some sort of evaluative social judgement, as I shall discuss in the next section.

Thus, on the view I propose, the clinical judgement that ' $x$ is infected with rubulavirus and $x$ has inflamed parotid glands, and ...' grounds the judgement that ' $x$ has a disease' just in case the clinical state of being infected with rubulavirus and having inflamed parotid glands, etc., is socially evaluated in a particular way. The specific nature of the social evaluations in question is not important for our present purposes, as I shall explain in the next section. In the meantime, let us note that the Epstein-style model as currently elaborated gives the grounding-conditions and framing principles for individual diseases, but does not yet constitute a general account of disease. But we can very easily give a framing principle comprising a comprehensive range of disjunctive (sets of) groundingconditions all anchored in just the same way; ' $x$ has (the clinical phenomena amounting to) Mumps' or ' $x$ has (...) Bulimia' or ' $x$ has (...) Hypertension' can each separately ground the judgement ' $x$ has a disease' just as long as the clinical facts corresponding to Mumps, Bulimia, and Hypertension meet the same set of anchoring conditions. ${ }^{11}$

Note that Epstein's schema can be used in this way for any familiar account of the disease concept: for Wakefield and his followers, the framing principle that cases of Mumps, Bulimia, Hypertension etc. count as diseases can be anchored by the fact that those conditions represent etiological dysfunctions which harm those who have them (Wakefield

\footnotetext{
${ }^{11}$ See Epstein (2015: 104-5).
} 
1992); for Boorse and adherents of the Bio-Statistical Theory, the framing principle can be anchored by the fact that those conditions deviate from statistically normal causal functioning in the reference population (Boorse 1975; Boorse 1977). What principally differentiates the various accounts, then, will be the particular set of background facts they think anchors the relevant framing principle. ${ }^{12}$ As a normativist, I think those background facts are evaluative in nature; and as a constructivist I-hold that they concern the making of judgements of a certain, evaluative sort. There are particular challenges to such a view that the analysis I present here solves, as I discuss in the final sections; but the analysis itself is of general application.

\section{The Scope of the Analysis}

From the simple opposition presented in the introduction, one might suppose that an equally simple definition of normativism follows: normativist views about disease are just those views about disease which are not naturalist. However, normativism encompasses a whole range of distinct positions, and cannot therefore be simply the negation of naturalism. It is not my aim here to elaborate or defend any particular version of normativism, ${ }^{13}$ but to provide normativism as a whole with a long-overdue elaboration of its metaphysical and semantic footing, as well as a defense against several influential lines of criticism. Accordingly, in this section, I will briefly survey the varieties of normativist approach, before sketching a 'toy' version of an unusually strong position. This will be used as a placeholder for the purposes of the subsequent discussion although, as I will note in passing, the grounding analysis I give can be applied mutatis mutandis to any position within the debate, including naturalism.

\footnotetext{
${ }^{12}$ Although we will also expect to see resulting differences in the frame principles themselves, which is what generates the familiar trade in problem cases and counter-examples.

${ }^{13}$ I have done so elsewhere; see Glackin (2010) and Glackin (2016).
} 
A good place to start in classifying theories of disease is with Alex Broadbent's recent taxonomy (Broadbent 2017). According to Broadbent, the standard way of contrasting naturalism and normativism conflates two separate distinctions, concerning the valueladenness and judgement-dependence of health facts. Thus, for instance, Elselijn Kingma characterises naturalists as claiming that 'health and disease are not determined by our subjective valuations of a state, but are purely a matter of biological fact', and normativists as 'reject[ing] this claim to objectivity and maintain[ing] that health and disease are essentially value-laden' (Kingma 2010: 242). But these positions, Broadbent notes, occupy only two of four possible 'quadrants'; one might also hold that such facts are value-laden but objective (e.g. Stempsey 2000) or, as Broadbent himself argues, value-free but dependent upon the subjective judgement of an observer.

A similar, but slightly more detailed, taxonomy is given by Jeremy Simon (2007), building upon R.M. Hare's classification of evaluative predicates (Hare 1997). On this view, describing a concept as 'value-laden' - so, for instance, rejecting the 'naturalist' view of disease - may mean variously that it is 'a subjective, irreducible (or irreducibly moral) or non-descriptive term' (Simon 2007: 352). We can take these in reverse order. A term is 'nondescriptive' in Hare's sense if its meaning cannot be given solely by its truth-conditions. For example, if a predicate is taken to describe a state of affairs and enjoin that we act upon it in some way - to possess both descriptive and 'prescriptive' or 'evaluative' content - it is nondescriptive. Thus, such a view of disease might characterise it in a particular manner and require that it be disapproved of in some way, or afforded medical intervention. ${ }^{14}$ Nondescriptivism further divides into rationalism and non-rationalism; a theory of disease is rationalist if the non-descriptive component of its meaning would necessarily be agreed

\footnotetext{
${ }^{14}$ Since 'non-descriptivists' are, and descriptivists are not, conceptually committed by their moral judgements to some further attitudes or actions, this distinction also corresponds to the metaethical distinction between motivational internalism and externalism. See e.g. Rosati (2016: §3.2).
} 
upon by all fully-informed rational agents (e.g. Engelhardt 1976: 266), ${ }^{15}$ and irrationalist if it would not (e.g. Clause, Culver, \& Gert 1997).

Among descriptivist accounts of disease, wherein the meaning of the term is entirely determined by its truth-conditions, Simon distinguishes between naturalist and nonnaturalist accounts. If non-naturalism in metaethics is the view that the truth-conditions of moral predicates are moral properties, not reducible to non-moral ones, then nonnaturalism about disease is the view that the truth-conditions of disease facts, too, are such properties. Simon is unable to find a clear example of such a view in the literature, though Caplan (1997) may count as an example.

Naturalism, then, in the broad sense employed by Simon, is the view that the truthconditions of health and disease facts are themselves, or are moral predicates reducible to, properties of the sort investigated and employed by the natural sciences. But there is a further distinction to be drawn; naturalism in Simon's sense may be either objectivist or subjectivist. That is, the naturalistic properties appealed to in an account of disease may exclude or include, respectively, subjective properties - such as attitudes or feelings - of the person or persons making the judgement of health or disease. Objective naturalism, then, in Simon's schema corresponds to 'naturalism' about health and disease as commonly conceived (e.g. Boorse 1975; Boorse 1977); subjective naturalism is the view occupying Broadbent's fourth quadrant, which Broadbent himself endorses. ${ }^{16}$

Let's presume for our current purposes that this represents a comprehensive overview of the available positions. My aim in this paper, as I say, is to provide a more solid footing for normativism in general, as well as to rebut some lines of criticism which have themselves been levelled against normativism without any particular regard for the nuanced distinctions Broadbent and Simon make. That is to say, I am not defending any particular version of

\footnotetext{
${ }_{15}$ This seems to be the correct characterisation of Fr. Stempsey's 'value-dependent realism', and by extension corresponds to Broadbent's third ('value-laden but objective') quadrant. Irrationalist nondescriptivism would then correspond to Broadbent's 'traditional normativism'.

${ }^{16}$ Simon suggests Nordenfelt (1987) and Whitbeck (1978) as further examples.
} 
normativism or social constructivism. Accordingly, I will here sketch an outline version of a particularly strong normativist position to serve as a placeholder for the rest of the discussion, though the discussion will not depend on any particular details of the sketch.

As Broadbent says, there are two elements to classically 'normativist' accounts of disease and health; the view that such claims are value-laden, and the view that they are subjective, or a matter of some particular observer's judgement. So both of these should be incorporated into our toy account. In the strongest set of views considered by Simon, the descriptive content of the judgement compelled some further attitudes or actions on the part of the judger; this should be incorporated as well. For the sake of generality, too, we should make the account metaethically neutral; nothing will be presumed for now about whether the values in question are the sort of thing fully-informed rational observers must agree about, or about their epistemic or ontological status. ${ }^{17}$ And finally, for reasons to be explained later, I will make no presumption as to whose subjective evaluative judgements we are concerned with here. Accordingly:

SOCIAL CONSTRUCTIVISM: A biological or behavioural state is judged to be a disease just in case it is regarded as: (a) possessing evaluative features $\left\{\Phi_{1}, \Phi_{2}, \Phi_{3}, \ldots\right\}$; and (b) therefore enjoining attitudes or actions $\left\{\Psi_{1}, \Psi_{2}, \Psi_{3}, \ldots\right\}$ on the part of others.

This view can be fleshed out however one wants; any biological or behavioural state which is generally regarded in our society as undesirable and therefore as demanding sympathy and medical intervention, for instance. I don't want to say that this particular position could be defended against all objections and counter-examples; clearly it could not. But even such an implausible form of normativism, as I will show, can be defended against some influential criticisms which naturalists have levelled against normativism in general.

\footnotetext{
${ }_{17}$ Thus, Social Constructivism is in Simon's terms a 'non-descriptivist' view, though it is neutral as between rationalist and irrationalist versions thereof.
} 


\section{The Politics and Semantics of Disagreement}

The formulation given for SOCIAL CONSTRUCTIVISM is deliberately schematic, leaving open the particular evaluative features and enjoined attitudes or actions involved in any particular constructivist view. But another lacuna is perhaps more important here, and worth noting. SOCIAL CONSTRUCTIVISM has a passive construction; the condition in question 'is regarded as' possessing some or other evaluative standards, and requiring some or other response. But who is doing the evaluation here? 'Regarded' by whom?

At the risk of exasperating some readers, no determinate answer is possible; but neither is one necessary. The analysis, remember, is of what is meant by the judgement that a given condition represents a disease. Accordingly, the evaluations we are interested in are just those of whoever is applying the disease concept. It seems clear that evaluations can be made both by individual persons, and by the (often heterogeneous, and/or overlapping) communities and social groups they form; ${ }^{18}$ so, at any rate, I shall assume. It therefore follows that both individuals and societies may make judgements about disease, and that these judgements may come into conflict.

The analysis thus throws up a further problem; whose judgements are, in practice, to count? Though it does not form part of the analysis, strictly speaking, I am going to suggest a broadly liberal approach to this question; in any society, for any given condition, there will be a variety of interested parties and stakeholders, forming three broad and overlapping groups. The first of these is the group of people with or otherwise directly affected by the condition; patients, but also family members, friends, neighbours, carers. The most precise way to characterise this group is perhaps; those who are affected by a particular instance or token of the condition. The second relevant group are the medical and scientific professionals who research and treat the condition; the third are the general public, who lack the more direct connections of the first two groups, but are expected to fund - whether

\footnotetext{
${ }^{18} \mathrm{How}$, exactly, this can be achieved is more controversial; this is yet another of the many topics addressed by Epstein (2015). For an overview of the issues, see Roth (2017).
} 
through taxation or charity - that treatment and research, as well as to tolerate and accommodate - or not - the existence and effect of the condition.

What a 'liberal' approach involves is the recognition that, since the criteria for a judgement of disease are evaluative, these groups - or the individuals that compose them may on (usually rare) occasion be unable to come to a consensus about some particular condition; and as liberal political theory holds, the best response to an irreconcilable clash of values is not to impose one faction's views on all parties, but to negotiate as wide as possible a modus vivendi, which will allow all parties to proceed on a basis of respectful disagreement, and tolerable compromise. ${ }^{19}$

So what is it that we are disagreeing about, when we disagree about our judgements of health and disease? There are two fundamental sorts of disagreement; intra-frame disagreements and extra-frame disagreements. And these reflect importantly different kinds of project of inquiry, corresponding to the 'constitution question' and 'status question' identified in section two.

What medical professionals are typically concerned with - and what we usually mean when we ask whether somebody is sick or healthy - are the intra-frame disagreements. In particular, they are interested in what Epstein terms the 'actual fact' inquiry, that is, 'whether the particular grounding facts obtain' or not (2015: 99). So when an oncologist asks whether her patient is sick, what she is interested in is whether or not his cells are cancerous, and how they are behaving. She is not concerned, qua oncologist, with the question of what the anchoring and grounding conditions are or should be, but only with whether her patient's condition meets them or is at risk of doing so. Clearly, to know whether the grounding

\footnotetext{
${ }^{19} \mathrm{cf}$. Rubin (2009); Glackin (2010). The claim here is that the tools of liberal political theory provide us with the means in principle to accommodate such differences, not the patently false claim that 'liberal' societies have in fact resolved all such disputes to general satisfaction. I thank an anonymous referee for pressing me to clarify this point. Note also that an irreconcilable clash of values' may be metaethically innocuous; a resolution may fail to be found not because there is none available, but because fallible humans are unable to find or agree upon it. So the discussion here is again neutral as between the various forms of normativism under consideration.
} 
conditions are met she must know what they are; 'somebody,' as Epstein notes, needs 'to have done the grounding enquiry well' (op. cit.: 100). But they are not themselves the objects of her diagnostic scrutiny; she is concerned simply with identifying, and if necessary changing, the grounding facts in particular cases.

However, 'actual fact' inquiries are not the only cases where intra-frame disagreements arise. A frame, remember, is a set of possible worlds, and within a frame we may also be interested in counterfactual questions; what would happen to the underlying clinical facts if we were to treat the patient - or the public as a whole - in such-and-such a way. Much medical research is concerned with what Epstein terms 'model-building' of this sort (ibid.); determining which interventions will affect when and how the grounding conditions are met, whether by curing individual patients, or by reducing the incidence across the population as a whole. And with the 'actual fact' inquiry of diagnosis out of the way, doctors also engage in this sort of counterfactual intra-frame disagreement when they go on to debate which treatment a given patient should receive.

There are two sorts of extra-frame disagreement, and we can deal with the less consequential first. Disagreements about the anchoring conditions concern the criteria for counting as a disease. ${ }^{20}$ This is what is at issue in the philosophical debates between naturalists and normativists, between proponents of the BST, the harmful dysfunction theory, and social constructivists; in virtue of what facts about leukaemia, scaphoid fracture, and schizophrenia do those count as diseases, whereas homosexuality, shortness, and pierced ears do not? This is what I referred to earlier as the 'general status question'; what characterises the kind 'disease'? So the question here is not the extensional one of which conditions are members of the class of diseases and which are not, but rather what the membership conditions of the class are. That, as I say, is a debate primarily of interest to philosophers; although it will have practical consequences, since the extension of the class will of course hang to some degree on which membership conditions we decide upon, the

${ }^{20} c f$. Epstein (2014). 
main test of a viable set of conditions is how well it satisfies our existing intuitions about the extension.

The more significant kind of extra-frame disagreement, then, concerns the grounding conditions; it involves, above all, the question of which biological or behavioural states are to count as diseases. And that is, in turn, to ask: which frame(s) we occupy; and so what the relevant framing principle(s) is (or are); and, lastly, what anchoring facts therefore obtain.

When we claim that ADHD, or leukaemia, is a disease, we assert our location in a frame, a set of possible worlds. The grounding facts will vary between worlds within the frame - Holger may or may not have ADHD, Jaki may or may not have leukaemia - but the grounding conditions are fixed, because the framing principle which specifies them is precisely what defines the frame. So whether Holger in particular has it or not, anyone with ADHD has a disease in this frame. When we change our minds about the question, we do not thereby 'cure' anybody of their ADHD; they remain in the same underlying state, we simply cease to classify it as a disease.

What we are disputing, then, when we disagree about whether ADHD is a disease, is the frame we inhabit. Somebody who denies that it is a disease takes us to occupy a different frame, one characterised by different grounding conditions. The grounding facts need not be in dispute; we can agree fully on all the clinical and behavioural facts regarding Holger, yet disagree whether or not he is therefore healthy. What is at issue is the correct framing principle to use, and that in turn depends on what the anchoring facts are. So the frame is a set of possible worlds defined by having the same anchoring facts as each other.

According to SOCIAL CONSTRUCTIVISM, the anchoring facts are evaluative; the framing principle 'cases of condition $X$ count as diseases' is anchored just in case condition $X$ is regarded as: (a) possessing evaluative features $\left\{\Phi_{1}, \Phi_{2}, \Phi_{3}, \ldots\right\}$; and (b) therefore enjoining attitudes or actions $\left\{\Psi_{1}, \Psi_{2}, \Psi_{3}, \ldots\right\}$ on the part of others. If ADHD is regarded in each of these ways, then the framing principle 'cases of ADHD count as diseases' applies; we occupy a frame in which any and all such cases are instances of disease. Other accounts of the 
anchoring conditions can produce the same result; if the Biostatistical Theory of disease is true, for instance, and ADHD represents a deviation from statistically-normal functioning in the relevant reference class, then the same framing principle will be anchored by that fact instead. So philosophers - depressingly or reassuringly, depending on one's temperament can disagree about the anchors while leaving both grounds and disease facts untouched.

Now, the sort of evaluative anchors that SOCIAL CONSTRUCTIVISM envisages may seem importantly different from Boorse's, particularly when it comes to disagreements, in the following way. ADHD either is or is not a deviation from statistical normality; people can disagree about the fact, but some of them are right, and the others are wrong. We are either in one frame or the other. What happens, on the other hand, if the anchors are evaluative? There can be persistent and intractable disagreement, as we have seen, between various groups and communities on any or all of the value judgements which might be made about a condition, including ex hypothesi the anchors. Does this mean that some groups will occupy one frame, and others another?

No; a frame is not a society, or a perspective. It is a set of possible worlds which either contains the actual world which all of us occupy, or does not. Tertium non datur; we are all either in a frame where cases of ADHD are cases of disease, or we are not. There's a straightforward way to cash this out if one adopts a cognitivist metaethics; value-claims are either true or false, so our evaluations either locate us in the correct frame, or an incorrect one. But my account doesn't entail cognitivism;21 I’ve spoken for the sake of simplicity and convenience (as well as fidelity to Epstein's model) of the framing principles as being anchored by 'anchoring facts', but there is no particular reason I can see that the anchors must be facts. The frames, which are the important thing, are still sets of possible worlds, and the grounds of disease-facts will still be clinical facts. A non-cognitivist, who doesn't regard evaluative judgements as truth-apt, could allow framing principles to be anchored by

\footnotetext{
${ }^{21}$ Recall; SOCIAL CONSTRUCTIVISM is neutral as between the (cognitivist) rationalist and (noncognitivist) irrationalist versions of Simon's non-descriptivism. The argument will likewise go through for both cognitivist and non-cognitivist versions of descriptivism too.
} 
the judgements' assertibility-conditions, or the desirability of their being followed, or whatever else she thinks makes one evaluative claim preferable to another. Indeed even error-theorists, who do regard such judgements as truth-apt - and systematically false - can use this route to get a more satisfactory account of which conditions are diseases and which are not.

Still, some will be concerned that one person's value-judgement really is not truer or more assertible than another's. I address this worry along with some related ones in the next, and penultimate, section.

\section{The Spectre of Relativism}

The most frequent, and troubling, objection to social constructivism about disease and to normativism more generally - is the charge that it leads to a sort of relativism, where just any condition judged by somebody or some group to be a disease thereby counts as one 'for them'. To see why such a relativism is troubling, rather than merely facile, consider the much-discussed case of 'drapetomania'. Some US psychiatrists of the nineteenth century applied that term to the purported mental disorder which was manifested in afflicted slaves attempting to run away (Cartwright 1851). Clearly, we do not consider this today to be a legitimate diagnostic category; nobody now regards fugitive slaves as thereby mentally ill, let alone as deserving of opprobrium or disapproval. But as a number of recent writers have pointed out, social constructivists have difficulty in saying what, exactly, is wrong with it (e.g. Ereshefsky 2009; Kukla 2014; Murphy 2008; Murphy 2015).22 If all there is to being healthy or diseased is to be approved or disapproved of, then 'you cannot say that those American doctors were wrong to call drapetomania a disease. All you can say is that we have different

${ }^{22}$ Kingma (2014: 598) raises, though without explicitly endorsing, a similar concern. 
values than those nineteenth century doctors' (Ereshefsky 2009: 224); given the values they and their society did have, their diagnosis was - there and then - correct.

This is disconcerting, to say the least. And the problem is not confined to such historical curiosities as drapetomania, or the use of the Soviet psychiatric establishment to oppress 'bourgeois deviationists' and other political enemies (ibid.). If a religious community continues to disapprove of homosexuality, and thus to class it as a disease, they are making no medical error; it is in that community a disease. Making health and disease a matter of social values seems to bring with it the consequence that different societies will have different diseases. And the unwelcome consequences encompass both the sinister and the absurd; do social constructivists really want to say that an ill patient can be made healthy, or a healthy person ill, merely by crossing a border between different diagnostic regimes? ${ }^{23}$

This in turn makes social constructivism, Rebecca Kukla has argued, '(un)appealing to those who wish to use the concept of health to help ground a normative social justice account' of the sort that much constructivism is motivated by (2014: 518). We expect the concept of disease to provide us with 'stable grounds for normative claims about rights, just social arrangements, and so forth' (ibid.); to establish that some condition is a disease is supposed to mean, among other things, that the bearer is excused the inconvenience it causes to others, and that resources are diverted to assist with it. To state that some condition is a disease, moreover, is supposed to explain why it is disvalued. The problem with embedding these points in the definition of disease, as I've done, is that it seems to get things backwards; the disease-status is supposed to be the reason we excuse, and divert, and disvalue, not a shorthand for saying that we have already, and independently, judged it appropriate to do so.

There's a broader point here, too, which Dominic Murphy has called 'the chief problem' for constructivism (Murphy 2008: 289; Murphy 2015); a satisfactory account of the

\footnotetext{
${ }^{23}$ Note the similarities here to the facile objection mentioned at the start of section two; $c f$. Lennox (1995: 500-1).
} 
disease-concept should tell us what is specifically medical about diseases, that differentiate them from other disvalued conditions such as being a pub bore, or the hapless devotee of a terrible football team. It won't do just to say that diseases are the disvalued conditions for which medical treatment is warranted; again, the fact that something is a disease is supposed to tell us why medical treatment is the appropriate intervention, and not just to record a determination we have already arrived at.

How should we respond to this set of linked problems? To begin with the last, that of explaining the demarcation between the medical and non-medical, I think a thoroughgoing normativist can and should simply refuse the demand for some extra facts which determine whether the appropriate response is medical or non-medical; the question can be settled by again appealing to our values.

Murphy challenges us to explain why as a disvalued, bodily condition which negatively affects the life prospects of sufferers, ugliness is not treated as a disorder (2008: 289);24 Rachel Cooper adds the cases of people of colour suffering racial discrimination, and gay people unable to have children. 'In all these cases the problems are relational,' she notes,

in that they can potentially be solved either by changing the individual or by making changes to society. Black people could have their skin bleached or society could stop being racist. The gay man could [undergo "corrective therapy", were any such therapy effective, and] have sex with a woman, ... or changes in adoption law could permit his becoming a parent. The ugly person can have plastic surgery or social notions of the beautiful or of qualities requisite in a partner could shift.25 (2007: 577)

Now, if Murphy's and Ereshefsky's explanatory challenge is to say why the medical options are not appropriate in each of these cases, there is no real reason why normativists should need to appeal to further facts, in addition to our moral values, to do so. There is nothing vacuously or viciously circular about justifying one course of action over another just

\footnotetext{
24 See also Ereshefsky (2009: 224).

25 The square parentheses denote material I have added to focus the point.
} 
by appeal to those values; to justify treating these predicaments as social or legal, rather than medical, all a normativist needs to say is that this is morally speaking the right thing to do. ${ }^{26}$

In a similar spirit, we can respond to Kukla's justificatory challenge by resisting the claim that anything over and above our ordinary moral judgements is required or, indeed, would be adequate here. Even if the disease-concept were entirely value-free, we could not for familiar Humean reasons ${ }^{27}$ - expect to infer from it without challenge normative conclusions about the treatment of patients. So it is no objection to SocIAL CONSTRUCTIVISM, or to any other normativist account of disease, that it does not provide us with an expedited route to socially just treatment of patients; no version of the concept is going to do that.

If we want social justice, in other words, we must do the hard, patient work of argument and advocacy for it; just agreeing on the descriptive facts will not be enough. But the grounding analysis I have given here can nevertheless allow the disease-concept to play something like the role Kukla wants. As we said in the previous section; to agree or disagree about the disease-status of a condition is to agree or disagree about the frame we occupy, and hence about the judgements which anchor it; for SOCIAL CONSTRUCTIVISM, those judgements are evaluative, and internally motivating. So the disease-concept can serve as 'stable grounds' for normative judgements etc. in this sense; insofar as we have agreed with others about a condition's status as a disease, SOCIAL CONSTRUCTIVISM conceptually commits us to agreeing - in broad strokes, at least - about how those who suffer from it ought to be treated. If our interlocutors won't agree that the condition is a disease, then the disease concept couldn’t stably ground agreed normative conclusions in any case. ${ }^{28}$

\footnotetext{
${ }^{26}$ This response may not be available to 'normativists' - in the sense of everybody bar traditional naturalists - whose accounts do not actually invoke values, such as Broadbent's value-free subjectivism, or what Simon terms 'subjective naturalism'. But these views are not vulnerable to Murphy's objection in the first place.

${ }^{27}$ But see also Lewens \& McMillan (2004).

${ }^{28}$ Clearly, this conceptual commitment is not shared by motivational externalist - 'descriptivist', in Simon's terminology - accounts of disease. A weaker version of the response to Kukla may be available to them; insofar as value-judgements are usually associated with commitments to action,
} 
What, finally, about the relativist worry; is it really true that we cannot say people like Samuel Cartwright were wrong about drapetomania, only that they do not share our values? It is hard to see why it would be. SOCIAL CONSTRUCTIVISM, along with the grounding analysis I've given here, aims to capture the nature of judgements about disease, but it in no way commits us to accepting them. After all, we are not committed to accepting the evaluative judgements which comprise them either, unless we have adopted a rather problematic metaethics. But most of us don't believe that the sort of moral values I've appealed to in defining the concept are relative. Some societies might treat homosexuality, or bourgeouis deviationism, or left-handedness as diseases; but they are wrong to do so in just the same way that some societies are wrong to allow slavery, or liquidate the kulaks, or leave their poor to starve. Likewise, there's no problem in imagining that a sick person will be treated as healthy upon crossing a border, or vice versa, so long as we suppose that one of the jurisdictions is in error. ${ }^{29}$

What the analysis I've given here claims is that when two individuals disagree whether ADHD, or deafness, or left-handedness is a disease they are employing the same concept of disease. What they are disagreeing about, if my analysis is correct, is how the condition should be regarded, how it should be evaluated. Unless we are moral relativists, however, we have no reason to suppose that both sets of evaluations are right. And if we are convinced

which externalists do not deny, getting agreement on them is typically an important precursor in practice to agreeing a course of action. But the Kukla objection, as I have said, makes an unrealistic demand on normativists in any case, to which tu quoque is a sufficient answer.

29 Can other varieties of 'normativism' make the same response to this objection? I think the subjectivist naturalist/value-free subjectivist position may run into difficulties here. If, as Broadbent argues, health and disease are observer-dependent 'secondary properties' on the model of colours then our dispute with Cartwright and the drapetomania theorists - or homophobic religious communities - may have no better prospect of a definitive answer than the question whether a particular shade of turquoise is 'really' to be grouped with the blues or the greens. I won't attempt to solve that problem on behalf of such theorists; it's enough for my present purposes that wholehearted normativists - normativists proper, one might say - have this defence available. 
moral relativists, it is hard to see why we might find medical relativism particularly objectionable.

\section{VI: Conclusion}

Previous accounts have neglected - whether rhetorically or substantively - the importance of biological facts to even a thoroughgoingly normativist interpretation of the public concept of disease, which has both seriously and needlessly impaired their credibility. I have attempted in this paper to rectify this failing by providing what is to my knowledge the first comprehensive attempt at an ontology and semantics of disease talk for normativism. This framework, which builds on Epstein's recent work in social ontology, is also reminiscent of some previous moves in the literature, notably Marc Ereshefsky's partitioning of the disease concept into 'state descriptions' and 'normative claims' (2009: 221, 225-7). However, by using them in an 'ordered' rather than a 'flat' ontology (Schaffer 2009: 354-6) - as the grounds and anchors, respectively, of disease - I've been able to incorporate both of those aspects into an account that preserves and clarifies, rather than abandons, the concept.

I've shown, further, that the chief objections to social constructivism about disease don't apply either to the strong outline account sketched here, nor to most other plausible versions of normativism. This advances the debate significantly beyond the familiar biostatistical/harmful dysfunction stalemate; while I haven’t tackled either of these two major theories directly, I have shown that there is no good reason to confine the discussion to them. Social constructivism and other strongly normativist accounts of disease are consequently real options, which can take seriously both the biological basis of disease and its inherently evaluative character, and cannot be as easily refuted as previous commentators have believed. They deserve a seat at the table. $3^{0}$

\footnotetext{
$3^{0}$ I am grateful to Brandon Conley, Adrian Currie, Hannah Galvin, Sinéad Glackin, Paul Griffiths, Joel Kueger, Louisa Owens, Tom Roberts, Carlos Santana, audiences at the University of Lancaster and
} 


\section{References}

Boorse, C. (1975) 'On the Distinction between Disease and Illness', Philosophy and Public Affairs, 5: 49-68.

-- (1977) 'Health as a Theoretical Concept', Philosophy of Science, 44: 542-73.

Broadbent, A. (2017) 'Health as a Secondary Property', The British Journal for the Philosophy of Science, advance publication online.

Brown, P. (1990) ‘The Name Game: Toward A Sociology of Diagnosis’, Journal of Mind and Behavior, 11: 385-406.

Cameron, R.P. (2016) ‘Do We Need Grounding?’ Inquiry, 59/4: 382-97.

Caplan, A.L. (1997) 'The Concepts of Health, Illness, and Disease', in R. Veatch (ed.) Medical Ethics, $2^{\text {nd }}$ edn. 57-73. Sudbury, MA: Jones and Bartlett.

Cartwright, S. (1851) 'Report on the Diseases and Peculiarities of the Negro Race', New Orleans Surgical and Medical Journal, 8: 691-715.

Cherry, M.J. (1996) 'Bioethics and the construction of medical reality', Journal of Medicine and Philosophy, 21: 357-73.

Clauser, K.D., Culver, C.M. and B. Gert (1997) 'Malady', in J.M. Humber and R.F. Almeder (eds.) What is Disease? 173-218. Totawa, NJ: Humana.

Cooper, R. (2007) 'Can it be a Good Thing to be Deaf?' Journal of Medicine and Philosophy, 32: $563-83$.

Engelhart, H.T. (1976) 'Ideology and Etiology', Journal of Medicine and Philosophy, 1: 2568.

Epstein, B. (2014) 'How Many Kinds of Glue Hold the Social World Together?' in M. Galloti and J. Michael (eds.), Perspectives on Social Ontology and Social Cognition, 41-55. Dordrecht: Springer.

the Sao Paulo ISHPSSB meeting in 2017, and several anonymous readers for helpful discussions of earlier drafts, and of this material more generally. 
-- (2015) The Ant Trap: Rebuilding the Foundations of the Social Sciences. Oxford: OUP.

Ereshefsky, M. (2009) 'Defining "health” and "disease”, Studies in History and Philosophy of Biological and Biomedical Sciences, 40: 221-7.

Glackin, S.N. (2010) 'Tolerance and Illness: The Politics of Medical and Psychiatric Classification', The Journal of Medicine and Philosophy, 35/4: 449-65.

-- (2016) 'Three Aristotelian Accounts of Disease and Disability', Journal of Applied Philosophy, 33/3: 311-26.

Goosens, W. (1980) ‘Values, Health and Medicine’, Philosophy of Science, 47: 100-15.

Hare, R.M. (1997) Sorting Out Ethics. Oxford: Clarendon.

Kincaid, H. (2008) 'Do We Need Theory to Study Disease? Lessons from Cancer Research and their Implications for Mental Illness', Perspectives in Biology and Medicine, 51/3: $367-78$.

Kingma, E. (2010) 'Paracetamol, Poison, and Polio: Why Boorse's Account of Function Fails to Distinguish Health and Disease', The British Journal for the Philosophy of Science, 61: $241-64$.

-- (2013) 'Health and Disease: Social Constructivism as a Combination of Naturalism and Normativism', in H. Carel and R. Cooper (eds.) Health, Illness, and Disease: Philoosphical Essays, 37-56. Abingdon: Routledge.

-- (2014) 'Naturalism about Health and Disease: Adding Nuance for Progress', Journal of Medicine and Philosophy, 39/6: 590-608.

Kukla, R. (2014) 'Medicalization, "Normal Function”, and the Definition of Health', in J.D. Arras, E. Fenton and R. Kukla (eds.) The Routledge Companion to Bioethics. London: Routledge.

Lennox, J. (1995) 'Health as an Objective Value', The Journal of Medicine and Philosophy, 20: $499-511$. 
Lewens, T. and J. McMillan (2004) 'Conduct and Compassion: Defining Disease', The Lancet, 363: 664 .

Margolis, J. (1976) 'The Concept of Disease', The Journal of Medicine and Philosophy, 1: $238-55$.

Murphy, D. (2008) 'Health and Disease', in S. Sarkar and A. Plutynski (eds.) A Companion to the Philosophy of Biology, 287-97. Oxford: Blackwell.

-- (2015) ‘Concepts of Disease and Health', in E.N. Zalta (ed.) The Stanford Encyclopedia of Philosophy, <https://plato.stanford.edu/archives/spr2015/entries/health-disease/> accessed 7 November 2018.

Nordenfelt, L. (1987) On the Nature of Health. Dordrecht: Reidel.

-- (2018) 'Functions and Health: Towards a Praxis-Oriented Concept of Health', Biological Theory, 13/1: 10-6.

Reiss, J. and R. Ankeny (2016) 'Philosophy of Medicine', in E.N. Zalta (ed.) The Stanford Encyclopedia of Philosophy, $<$ https://plato.stanford.edu/archives/sum2016/entries/medicine/> accessed 7 November 2018.

Reznek, L. (1987) The Nature of Disease. New York: Routledge.

Rosati, C.S. (2016) 'Moral Motivation', in E.N. Zalta (ed.) The Stanford Encyclopedia of Philosophy, < https://plato.stanford.edu/entries/moral-motivation/> accessed 7 November 2018.

Roth, A.S. (2017) ‘Shared Agency’, in E.N. Zalta (ed.) The Stanford Encyclopedia of Philosophy, <https://plato.stanford.edu/archives/sum2017/entries/shared-agency/> accessed 7 November 2018. 
Rubin, J. (2009) 'Political Liberalism and Values-Based Practice: Processes Above Outcomes or Rediscovering the Priority of the Right Over the Good', Philosophy, Psychiatry, and Psychology, 15/2: 117-23.

Schaffer, J. (2009) ‘On What Grounds What,' in D. Manley, D.J. Chalmers, and R. Wasserman (eds.), Metametaphysics: New Essays on the Foundations of Ontology, 347-83. Oxford: OUP.

-- (2017) 'Social Construction as Grounding; or: Fundamentality for Feminists, a Reply to Barnes and Mikkola', Philosophical Studies, 174/10: 2449-65.

-- (forthcoming) ‘Anchoring as Grounding: On Epstein’s The Ant Trap', Philosophy and Phenomenological Research.

Schliesser, E. (2015) 'On the Development of Social Kinds: On Brian Epstein's The Ant Trap', Digressions \& Impressions blog $29^{\text {th }}$ July 2015, <http://digressionsnimpressions.typepad.com/digressionsimpressions/2015/o7/onsocialkind-development.html> accessed 7 November 2018.

Simon, J. (2007) 'Beyond Naturalism and Normativism: Reconceiving the "Disease” Debate', Philosophical Papers, 36/3: 343-70.

Stempsey, W.E. (2000) Disease and Diagnosis: Value-Dependent Realism. Dordrecht: Springer.

Szasz, T. (1960) 'The Myth of Mental Illness', American Psychologist, 15: 113-8.

Wakefield, J.C. (1992) 'Disorder as Harmful Dysfunction: A Conceptual Critique of DSM IIIR's Definition of Mental Disorder', Psychological Review, 99: 232-47.

Whitbeck, C. (1978) ‘Four Basic Concepts of Medical Science’, PSA 1978, 1: 210-22.

Wilson, J. (2014) ‘No Work for a Theory of Grounding’, Inquiry, 57: 535-579 
World Health Organization (2016) International Classification of Diseases. WHO website; <http://apps.who.int/classifications/icd10/browse/2016/en> accessed 7 November 2018.

University of Exeter, UK 